\title{
Design, construction and characterization of prourokinase mutant engineered by introduction of special Lys-Gly-Asp-Trp-motif
}

\author{
Jian Jing \\ Beijing Key Laboratory of Genetic Engineering and Biotechnology, College of Life Sciences, Beijing Normal University, Beijing, \\ China \\ Email: jiing@bnu.edu.cn
}

Received 13 January 2013; revised 5 March 2013; accepted 11 April 2013

Copyright (C) 2013 Jian Jing. This is an open access article distributed under the Creative Commons Attribution License, which permits unrestricted use, distribution, and reproduction in any medium, provided the original work is properly cited.

\begin{abstract}
A recombinant prourokinase chimera was constructed by introduction of Lys-Gly-Asp-Trp-motif between Gly118 and Ile119 among the kringle domain. The structure of designed protein was predicted and simulated. The recombinant prourokinase chimera was produced in insect cell sf9 with baculovirusexpression vector and existed as active form. Chimera protein was purified by affinity chromatography coupled with antibody. The special activity of the chimera was $90,000 \mathrm{IU} / \mathrm{mg}$ detected by fibrin plate determination. It was also shown that chimera inhibited ADP-induced platelet aggregation in a concentration depenent manner. These results showed the prourokinase chimera exhibited not only high fibrinolytic activity but also had anti-thrombosis function.
\end{abstract}

Keywords: Prourokinase; Lys-Gly-Asp-Trp-motif; Baculovirus-Insect Cell Expression System; Fibrinolytic Activity; Anti-Thrombosis Activity

\section{INTRODUCTION}

Prourokinase, the single chain urokinase-type plasminogen activator, is a glycoprotein of 411 amino acids with glycoside on Asn302 and can be conversed into urokinase by cleavage of the Lys158-Ile159 peptide bond [1]. Native prourokinase can be purified from urine [2], plasma [3], kindey cells [4], and certain tumor cells [5]. Recombinant prourokinase was produced in E. coli [6], chinese hamster ovary cell [7], COS-1 cells [8] etc. Prourokinase is a kind of thrombolytic agent to be adopted during the treatment of thrombosis-related diseases such as AMI, etc.
Disintegrin barbourin is a polypeptide of 100 amino acids with high inhibitory activity of platelet aggregation [9]. The Lys-Gly-Asp-motif (KGD) located at functional loop region of barbourin and can specially recognize and bind the fibrinogen-receptor on the cell surface of stimulated platelets [10].

Abnormal platelet aggregation results in the reooclusion after thrombolytic treatment [11]. This is serious side-effect of thrombolytic treatment adopted most kind of thrombolytic agent such as prourokinase, t-PA, etc. To improve treatment effect of prourokinase as thrombolytic agent, multi-functional prourokinase was constructed with high fibrinolytic activity and high anti-thrombosis activity.

Based on molecular simulation, the special Lys-GlyAsp-motif originated from disintegrin barbourin was designed to introduce the kringle domain of prourokinase. Then, the whole-length prourokinase containing LysGly-Asp-motif (KGD-prourokinase chimera) was constructed with recombinant DNA method and also was expressed in insect cell sf9 cells. The expressed product exist as active form and was collected and purified by affinity-chromatography. The biological activities including fibrinolytic activity and anti-platelet aggregation activity were determined.

\section{MATERIALS AND METHODS}

\subsection{Materials}

The prourokinase clone was generated in our previous research. Transfer vector $\mathrm{pFBac}$ and E. coli DH10Bac waas purchased from Invitrogen (Hong Kong) Ltd. Sepharose 4B were bought from Pharmacia(Sweden). Anti-prourokinase antibody was a gift from Prof. WeiYan Yue of Institute of Biotechnology (Beijing). 


\subsection{Simulation of the KGD-Prourokinase Structure}

The structure of the KGD-prourokinase was simulated with sgi workstation using Insight II software. Structural simulation was carried out with the data of NMR structure of native human prourokinase (Protein Data Bank, Brookheaven, CA). The Biopolymer module was employed to add the KGDW sequence between the Gly118 and Ile119 sites of prourokinase structure. The Builder module was employed to carry out structural optimization (iterations: 1000; derivative: 0.01).

\subsection{Construction of the KGD-proUK Mutant Gene}

The multiple steps of polymerase chain reaction method was employed to construct mutant KGD-containing proUK gene. The sequences of the primers were as follows: CCCAA GCTTGATATCATG A (Primer 1, 5'-primer); GACAAG CGGCTTTAGCCA GTCCCCTTTGCCCACCTGCACATA (Primer 2, mutprimer); CTAAAGCCGCTTGTC (Primer 3, complementary to the mut-primer); GTGGCGCTGATCACCC (Primer 4, complementary to the encoding region of $672-688$ sequence of proUK gene, 3'-primer). Primers 1 and 2 were used to obtain upstream DNA fragment, and Primer 3 and 4 were used to obtain downstream DNA fragment. Then, the above two DNA fragments were mixed and anneled with the Primers 1 and 4 to obtain largemolucular-KGD-containing sequence. Then, by digestion of HindIII and BclI, the above DNA fragment was inserted into the corresponding region of native proUK gene and whole-length KGD-proUK gene could be obtained. The DNA sequencing assay was used to determine the gene structure.

\subsection{Expression of the KGD-proUK Gene with Baculovirus-Insect Cell System}

Polyhedrin-fusion vector $\mathrm{pFBac}$, was used as a trasnfer vector. Recombinant transfer vector $\mathrm{pFBac}-\mathrm{KGD}$-proUK was constructed by insertion of KGD-proUK gene into BamHI and EcoRI sites among the multiple cloning site of pFBac [12]. The pFBac-KGD-proUK was introduced into E. coli DH10Bac to get recombinant baculovirus DNA inserted with KGD-proUK gene under polyhedrin promoter [13]. The recombinant baculovirus DNA was isolated and transfected into sf9 insect cells and KGD-proUK was expressed transiently in insect cells. By signal peptide, expressed KGD-proUK protein was secreted into culture medium after 5 - 7 days postinfection. The fibrinolytic activtiy assay was used to determine the locus of expressed products.

\subsection{Purification of KGD-proUK Chimera}

The culture medium and infected insect cells were collected 5 - 7 days post-infection and condensed. The protein product was purified by fractional precipitation with 0.2 0.45 ammonium sulphate and by immunoaffinity chromatography [7]. The immunoaffinity chromatography column was made by coupled anti-proUK antibody to activated sepharose 4B. The homogeneity of purified product was assayed by western-blotting and PAGE electrophoresis.

\subsection{Fibrinolytic Activity Measurement on Fibrin Plate}

Specific fibrinolytic activity of KGD-proUK chimera was measured on fibrin plates by comparison with the International Reference Preparation for Urokinase [14]. $1 \%(\mathrm{w} / \mathrm{v})$ agar solution containing plasminogen-free fibrinogen was prepared. The mixture was immediately transferred to a sterile dish into which $53 \mathrm{uL}$ of 30 $\mathrm{U} \cdot \mathrm{mL}^{-1}$ thrombin and $20 \mathrm{uL}$ of $2 \mathrm{U} \cdot \mathrm{mL}^{-1}$ plasminogen were added, respectively. The fibrin plates were mixed gently and cooled to room temperature. Uniform wells were punched and sample was diluted and added to well, respectively. The diameters of these plaques were measured after incubation at $37^{\circ} \mathrm{C}$ for $16 \mathrm{~h}$. The content of KGD-proUK was determined by Bradford method [15].

\subsection{Inhibition of Platelet Aggregation}

Fresh rabbit blood was anticoagulated with $0.01 \mathrm{M}$ sodium citrate $(10 \% \mathrm{v} / \mathrm{v}), \mathrm{pH} 7.4$, and centrifuged at $150 \mathrm{~g}$ at $25^{\circ} \mathrm{C}$ for $10 \mathrm{~min}$. The supernatant was collected as platelet-rich plasma. The protein samples were dissolved in $0.9 \% \mathrm{NaCl}$. Platelet-rich plasma, $300 \mathrm{uL}$, was incubated with $25 \mathrm{uL}$ of various concentrations of protein samples at $37^{\circ} \mathrm{C}$ for $2 \mathrm{~min}$ before addition of $25 \mathrm{uL}$ of $100 \mathrm{uM}$ adenosine 5'-diphophate. The inhibition of platelet aggregation was determined by light transmission measurement. The IC50 value was calculated by linear regression.

\section{RESULTS}

\subsection{Molecular Simulation and Modelling of KGD-Prourokinase Chimera}

The structural simulation and homology modeling of the KGD-prourokinase chimera was carried out with the sgi-workstation using Insight II-software based on detailed structural information of native prourokinase and the disintegrin barbourin [10]. To protect previous enzymatic activity of prourokinase, foreign KGD-containing motif was designed to introduce between Gly118 site and Ile119 site among Kringle domain which is far 
away from the proteolytic active region of prourokinase and would not affect previous enzymatic domain structure. The flanking amino acid Trp at the carboxylterminus of KGD-motif was also introduced to help KGD-motif originated from disintegrin barbourin exhibit active conformation. The sinulated structure (Figure 1) of the KGD- prourokinase chimera protein demonstrates that the KGDW-peptide introduced between the Gly118 and Ile119 site among Kringle domain of natvie prourokinase lies on the surface of prourokinase molecule and the side-chains of the KGD sequence are extened to the outside of loop structure and exhibits its functional motif to interact with the glycoprotein IIb/IIIa receptor, known as fibrinogen receptor. The structural property of the KGD-containing functional motif provides necessary requirements of recognition and interaction with the glycoprotein IIb/IIIa receptor, known as fibrinogen receptor, on platelet cell surface. On the other side, the other parts of prourokinase, especially enzymatic domain, didn't change obviously and remained the same as native conformation of prourokinase almostly. Then, Proteolytic activity of prourokinase as a kind of protease to activate plasminogen to plasmin can be still retained. So there is great possibility to obtain a novel multi-functional thrombolytic agent both with potent fibrinolytic activity and also with high anti-thrombosis activity.

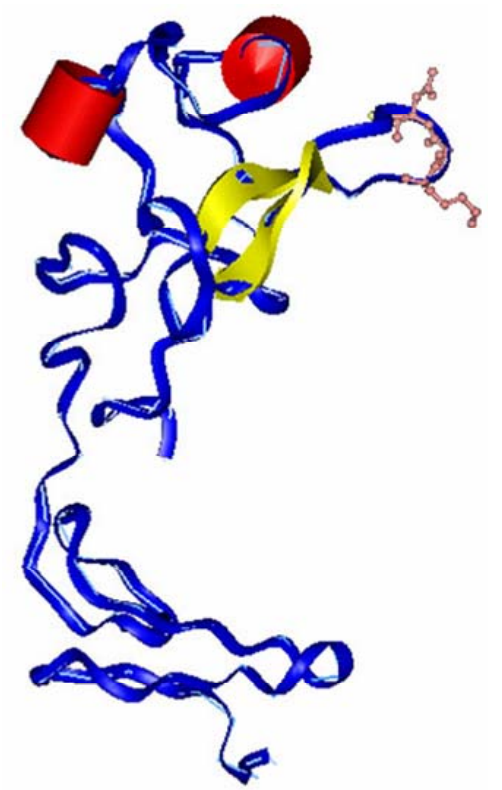

Figure 1. Simulation of three-dimensional structure of the KGD-prourokinase. Peptide backbone is shown as along slender coil shaded in blue with the KGD sequence (including the side-chians) highlighted. The $\alpha$-helix is represented in red and $\beta$ sheet is shown in yellow.

\subsection{Construction and Expression of the KGD-Prourokinase Gene}

Routine recombinant DNA techniques were used to construct this chimeric gene and the gene was overexpressed in insect sf9 cells with constructed recombinant baculovirus expression vector. The signal peptide located at the N-terminus of encoding-box of the KGDprourokinase chimeric gene. In order to introduce the whole mutant prourokinase gene (including signal peptide sequence) into baculovirus genome and put it under the control of the polyhedrin promoter, a baculovirusderived transfer vector $\mathrm{pFBac}$ was used as cloning vector for KGD-prourokinase gene. Based on the sequence homology of $\mathrm{Ph}$ promoter and its flanking region in pFBac and baculovirus DNA, the KGD-prourokinase encoding-box replaced the polyhedrin gene encodingbox of baculovirus DNA via in vivo homologous transpozon recombination. The polyhedrin-negative recombinant virus DNA was isolated and identified by PCR method using special 5'-primer and 3'-primer of native prourokinase gene, as shown in Figure 2, was named as BacV-KGD-prouk, respectively. The DNA sequence of BacV-KGD-prouk was assayed as shown in Figure 3, which is in aggrement as expected. When insect cells were infected with the cloned recombinant baculoviruses

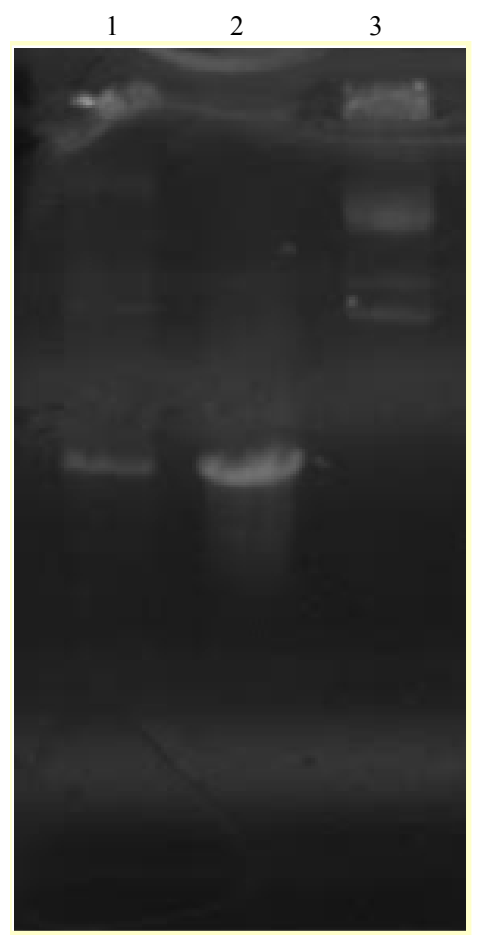

Figure 2. Determination of recombinant baculovirus containing KGDprourokinase chimera gene by PCR method. Lanes 1, 2, KGD-prourokinase chimera gene; Lane 3 , the recombinant baculovirus DNA. 


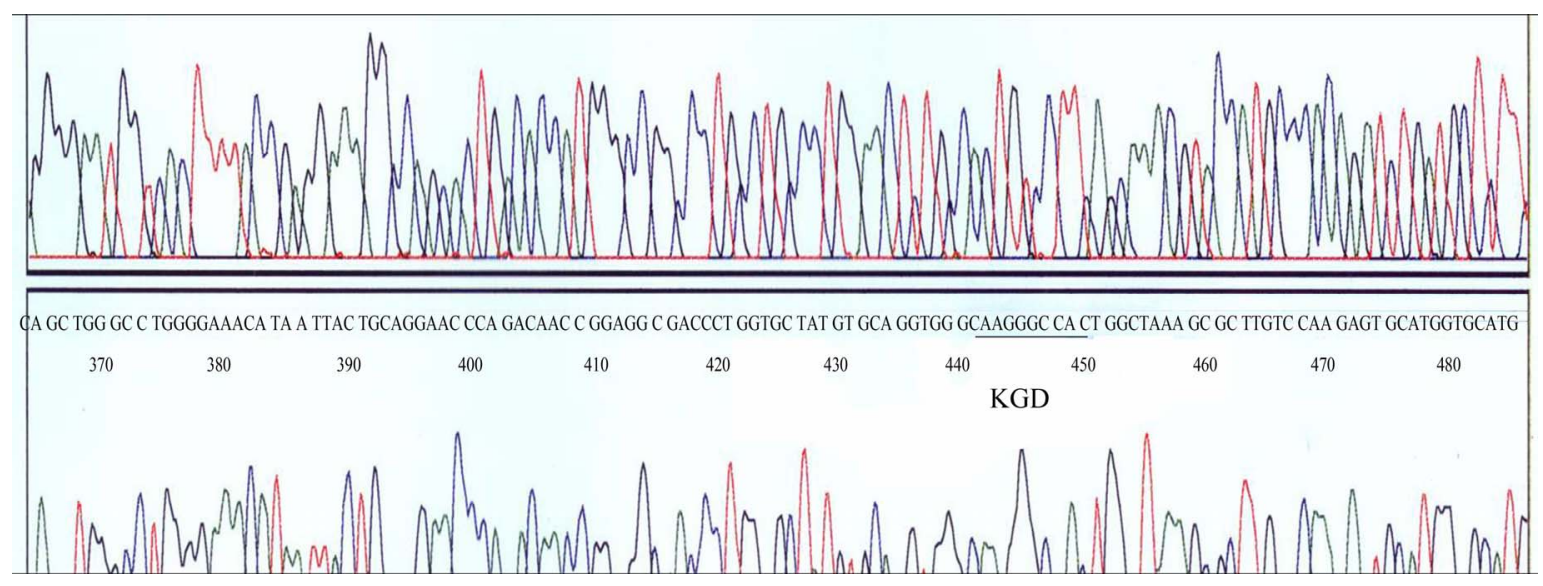

Figure 3. DNA sequence analysis of KGD-prourokinase gene.

at 10 plaque-foming units (pfu) per cell, fibrinolytic activity in the medium was detected at 48 hours post infection (hpi) using fibrin-plate assay. The highest activities, which was obtained at $168 \mathrm{hpi}$, were estimated to be $1200 \mathrm{IU} / 10^{6}$ cells respectively. Fibrinolytic activities remained cell-associated were about $100 \mathrm{IU} / 10^{6}$ cells or less, at $168 \mathrm{hpi}$, as shown in Figure 4. This result also suggested that more than $90 \%$ of the expressed recombinant KGD-prourokinase protein was secreted into the culture medium.

\subsection{Purification and Characterization of the KGD-Prourokinase}

The culture medium of infected insect cells sf9 was collected and centrifuged to remove un-resolved materials. Then, the supernatant was ultrafiltrated to condensed the sample solution containing the KGD-prourokinase chimera proteins. The immunological activity of KGDprourokinase recombinant protein expressed by insect cells was analyzed by Western blot using anti-proUK antibody, as shown in Figure 5. The major band of protein with molecular mass $50 \mathrm{kDa}$ should be Asn 302 glycosylated mutant prourokinase. The other band of 33 $\mathrm{kDa}$ is thought to be partially degraded product of the KGD-prourokinase, as same as that of native prourokinase. The result demonstrated that both KGD-prourokinase and partially degraded product remains the immuno-activity as same as native prourokinase which can be recognized and binded by anti-proUK antibody. This also suggested that the affinity chromatography coupled with anti-proUK antibody could be adopted to purify expressed recombinant KGD-prourokinase protein. Sephacryl S100 chromatography was first used to separate expressed KGD-prourokinase chimera protein. The KGD-prourokinase was further purified by affinity chromatography based on Sepharose CL-4B coupled with anti-proUK antibody. Purified KGD-prourokinase recombinant protein was determined by both SDS-PAGE

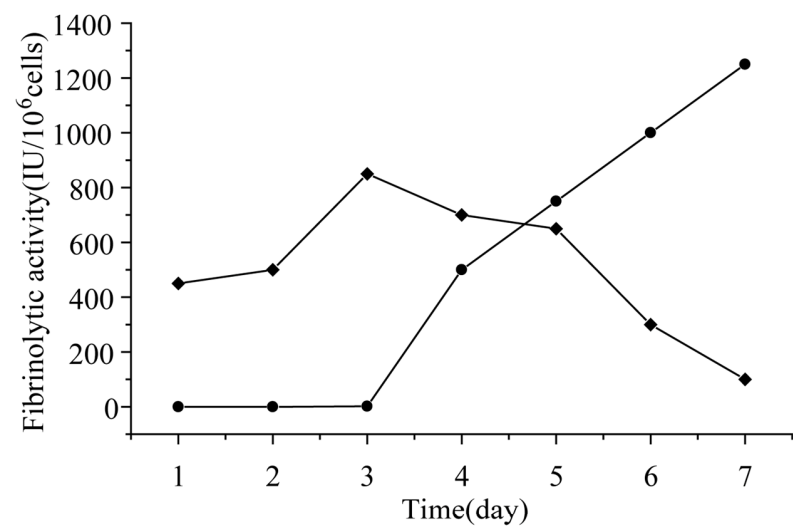

Figure 4. Time courses of mutant prourokinase expression. (•) cell culture supernatant from infected sf9 cells; $(\bullet)$ infected sf9 cells.

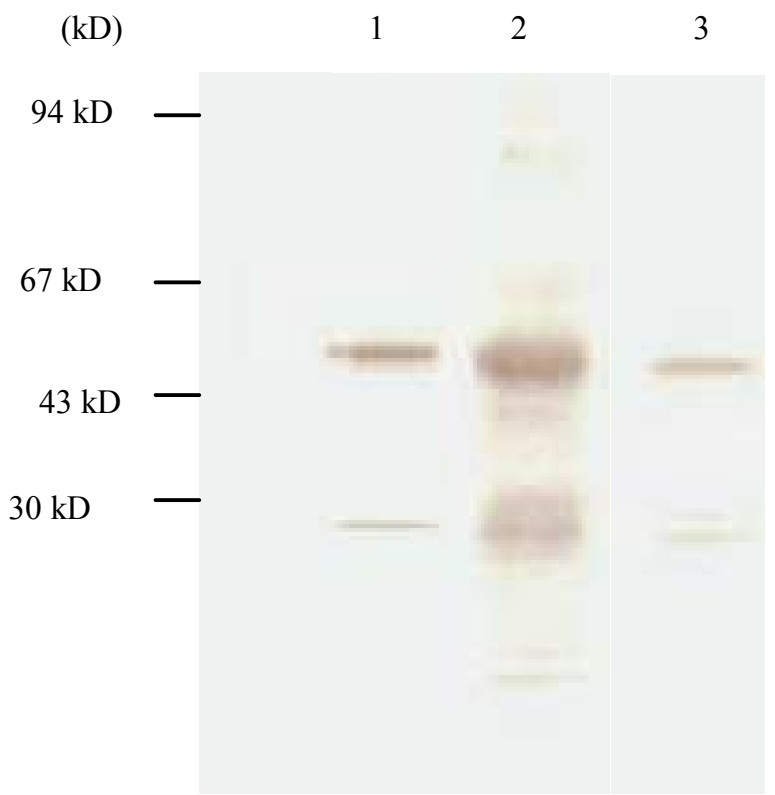

Figure 5. Western-blotting analysis of condensed culture components at late culture time (144 hpi). Lane 1, cytoplasm component; Lane 2, native proUK; Lane 3, medium component. 
and western-blotting assay also (Figure 6). The concentration of purified KGD-prourokinase-containing solution was determined by the Bradford method as described [15] and fibrinolytic activity unit of purified KGD-prourokinase was determined by fibrin-plate assay as described [14]. Based on above data, specific activity of fibrinolysis of recombinant KGD-prourokinase was calculated as $80,000 \mathrm{IU} / \mathrm{mg}$, with the control of native prourokinase, $10,000 \mathrm{IU} / \mathrm{mg}$. The result shows that recombinant KGD-prourokinase retained most of fibrinolytic activity as compared with native prourokinase and the stereo-structure of prourokinase enzymatic region was almost the same as that of native molecule and not affected by foregin Lys-Gly-Asp-motif introduced, which is in agreement with our expectation based on homology modelling and structural simulatin. The inhibitory activity of adenosine 5'-diphosphate-induced human platelet aggregation by the KGD-prourokinase was tested, as shown in Figure 7. Light transmission of ADP-induced platelet aggregation was detected and demonstrate that the KGD-prourokinase shows high platelet aggregation inhibitory activity (data not shown). The IC50 value calculated is about $9.6 \mathrm{uM}$, while native human prourokinase, under the same conditions, shows no inhibitory activity of the platelet aggregation (Figure 7). The results suggested that the KGDW-motif introduced between the Gly118 site and Ile119 site of native human prourokinase exhibits its functional conformation, and can interact directly with corresponding glycoprotein $\mathrm{IIb} / \mathrm{III}$ a receptor on the platelet cell surface. The potent inhibitory activity of the KGD-prourokinase agrees well with our expectation based on the result of structural simulation of the KGD-motif among chimera protein.

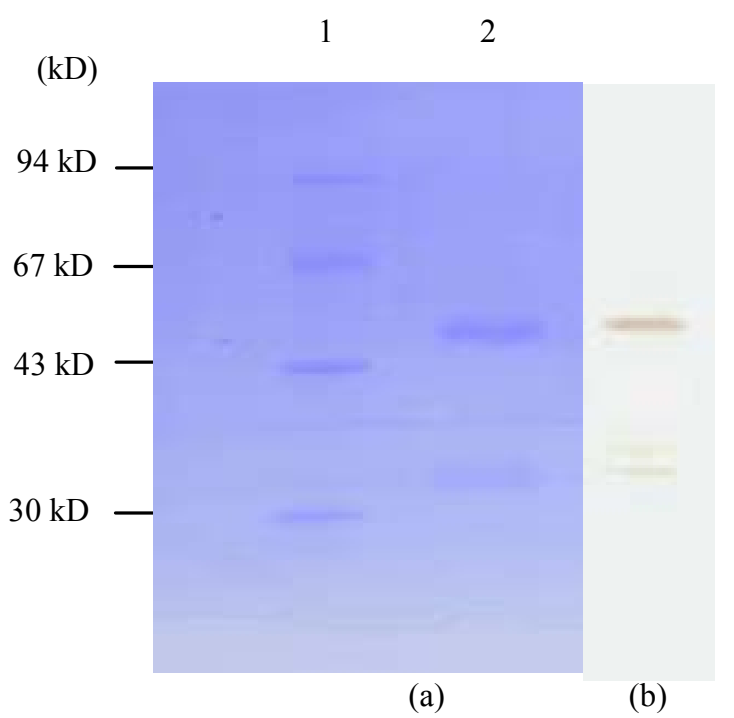

Figure 6. 12\% SDS-PAGE (a) and western-blotting (b) of purified KGD-prourokinase. Lane 1, molecular weight protein marker; Lane 2, KGD-prourokinase.

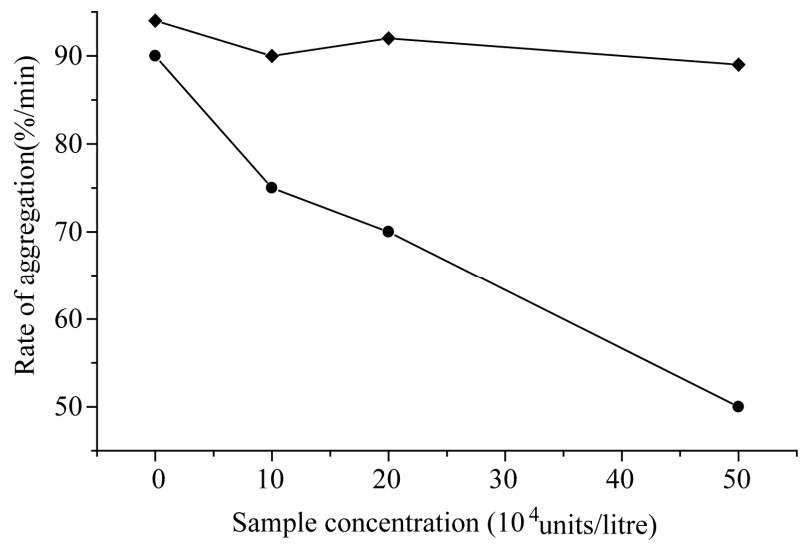

Figure 7. Inhibitory curve of adenosine 5'-diphosphate-induced platelet aggregation by the KGD-prourokinase. $(\bullet)$ KGDprourokinase; $(\bullet)$ native human prourokinase.

\section{DISCUSSION}

Pharmacological dissolution of established thrombi has become a well accepted therapeutic procedure for many patients who developed myocardial infarction [16]. However, $10 \%-30 \%$ of patients experience acute coronary reocclusion following thrombolysis $[17,18]$. Systemic fibrinogenolysis and consequent bleeding encountered frequently [19]. The interaction between platelet fibrinogen-receptor and matrix ligands is final common pathway involved in platelet aggregation and rethrombosis [11]. The rational use of platelet fibrino-gen-receptor antagonists in combination with fibrinolytic agents represents an attractive approach in the context of thrombolytic therapy $[20,21]$. Disintegrin barbourin is potent inhibitory agent of platelet aggregation by recognizing and binding specially platelet fibrinogen-receptor through its functional Lys-Gly-Asp-motif.

Based on structural data of barbourin and prourokinase, a novel thrombolytic agent was designed with fibrinolytic activity and anti-thrombosis activity (anti-platelet aggregation activity). The special Lys-Gly-Asp-motif originated from functional region of barbourin was introduced between Gly118 and Ile119 of Kringle domain of natvie prourorkinase. The fibrinolytic activity data suggested that most of fibrinolytic activity was retained and the introduction of KGD-motif didn't affect obviously the enzymatic region of prourokinase molecule. This is accordance with the data of molecular simulation of KGD-prourokinase chimera. On the other side, KGD-prourokinase chimera exhibited potent inhibitory activity of ADP-induced platelet aggregation and suggested that introduced KGD-motif could recognize and interact with GPIIb/IIIa receptor on the cell surface of platelet.

In all, KGD-prourokinase chimera has great possibility to be adopted as a novel thrombolytic agent in clinical usage with potent fibrinolytic activity and high anti- 
thrombosis activity.

\section{ACKNOWLEDGEMENTS}

We thank especially Prof. Weiruan Yue, for helpful discussion about this work. Dr. Yinye Wang, for platelet aggregation assay. This work was supported by a grant from Nature Science Foundation of China (30540071, 2006) and Fundamental Research Fund for the Central Universities of China.

\section{REFERENCES}

[1] Gunzler, V.A., Steffens, G.J., Otting, F., et al. (1982) Structural relationship between human high and low molecular mass urokinase. Hoppe-Seyler's Zeitschrift für physiologische Chemie, 363, 133-141. doi: $10.1515 / \mathrm{bchm} 2.1982 .363 .1 .133$

[2] Husain, S.S., Gurewich, V. and Liinsik, B. (1983) Purification and partial characterization of a single-chain high-molecular-weight form of urokinase. Archives of Biochemistry and Biophysics, 220, 31-38. doi:10.1016/0003-9861(83)90383-1

[3] Wan, T.C., Sssowski, L., Reich, E., (1982) A proenzyme form of human urokinase. Journal of Biological Chemistry, 257, 7262-7268.

[4] Toki, N. and Sumi, H. (1982) Urinary trypsin inhibitor and urokinase activities in renal diseases. Acta Haematol, 45, 119-128.

[5] Wun, T.C., Schlenning, W.D. and Reich, E. (1982) Isolation and characterization of urokinase from human plasma. Journal of Biological Chemistry, 257, 32763283.

[6] Homes, W.E., Pennica, D., Blaber, M., Rey, M.W., Guenzler, W.M., Staffen, G.J. and Heyneker, H.L. (1985) Cloning and expression of the gene for pro-urokinase in Escherichia coli. Biotechnology, 3, 923-929. doi:10.1038/nbt1085-923

[7] Nelles, L., Lijnen, H.R., Collen, D. and Holmes, W.E., (1987) Characterization of recombinant human single chain urokinase-type plasminogen activator mutants. Journal of Biological Chemistry, 262, 5682-5689.

[8] Cheng, S.M., Lee, S.G. and Kalyan, N.K. (1988) Isolation of a human cDNA of urokinase and its expression in COS-1 cells. Gene, 679, 357-363. doi:10.1016/0378-1119(88)90447-7

[9] Scarborough, R., Rose, J.W., Hsu, M.A., Phillips, D.R., Fried, V.A., Campbell, A.M., Nannizzi, L. and Charo, I.F. (1991) Barbourin. A GPIIb/IIIa-specific integrin antagonist from the venom of Sistrurus $m$ barbouri. Journal of Biological Chemistry, 566, 9359-9362.

[10] Minoux, H., Chipot, C., Brown, D. and Maigret, B. (2000)
Structural analysis of the KGD sequence loop of barbourin an alphallbbeta3-specific disintegrin. Journal of Computer-Aided Molecular Design, 14, 317-327. doi:10.1023/A:1008182011731

[11] Plow, E.F., Marguerie, G. and Ginsberg, M. (1987) Fibrinogen, fibrinogen receptors, and the peptides that inhibit these interactions. Biochemical Pharmacology, 36, 4036-4040. doi:10.1016/0006-2952(87)90558-2

[12] Maeda, S. (1989) Gene transfer vectors of a baculovirus, Bombyx mori unclear polyhedrosis virus, and their use for expression of foregn genes in insect cells [C]. In: Mitsuhashi, J., Ed., Invertebrate Cell System Appliactions, CRC Press, Boca Raton, 163.

[13] O'Rielly, D.R., Miller, L.K. and Luckow, V.A. (1992) Baculovirus expression vectors, a laboratory Manuual [M]. Freeman, New York.

[14] Astrup, T. and Mullertz, S. (1952) The fibrin plate method for estimating fibrinolytic activity. Archives of Biochemistry and Biophysics, 40, 346-351. doi:10.1016/0003-9861(52)90121-5

[15] Bradford, M.M. (1976) A rapid and sensitive method for quantitation of microgram quantities of protein utilizing the principle of protein-dye-binding. Analytical Biochemistry, 72, 248-54. doi:10.1016/0003-2697(76)90527-3

[16] Bode, C., Nordt, T.K. and Runge, M.S. (1994) Thrombolytic therapy in myocardial infarction. Annals of $\mathrm{He}$ matology, 69, 35-40. doi:10.1007/BF02215957

[17] Rapaport, E. (1991) Thrombolysis, anticoagulation, and reocclusion. American Journal of Cardiology, 68, 17E22E. doi:10.1016/0002-9149(91)90301-Z

[18] Eisenberg, P.R. (1993) Mechanisms of reocclusion after coronary thrombolysis. Zeitschrift für Kardiologie, 82, Suppl. 2, 175-178.

[19] Dennis, M.S., Henzel, W.J., Pitti, R.M., Lipari, M.T., Napier, M.A., Deisher, T., Bunting, S. and Lazarus, R.A. (1989) Platelet glycoprotein IIb-IIIa protein antagonists from snake venoms: Evidence for a family of platelet-aggregation inhibitors. Proceedings of the National Academy of Sciences, 87, 2471-2475. doi:10.1073/pnas.87.7.2471

[20] Shebuski, R.J., Stabilito, I.J., Sitko, G.R. and Polokoff, M.H. (1990) Acceleration of recombinant tissue-type plasminogen activator induced thrombolysis and prevention of reocclusion by the combination of heparin and the Arg-Gly-Asp-containing peptide bitistatin in a canine model of coronary thrombosis. Circulation, 82, 169-177. doi:10.1161/01.CIR.82.1.169

[21] Shebuski, R.J., Berry, D.E., Bennett, D.B., Storer, B.L., Ali, F. and Samanen, J. (1989) Demonstration of Ac-ArgGly-Asp-Ser-NH2 as an antiaggregatory agent in the dog intracoronary administration. Thrombos Haemostas, 61, 183-188. 